\title{
ESTE É NOSSO CORPO A TERRA: UMA CONVERSA SOBRE MODOS DE CUIDADOS AVÁ GUARANI/ÑANDEVA DE PORTO LINDO (JAKAREY) YVY KATU
}

\author{
This is our body to earth: a conversation about modes of care Avá \\ Guarani/Ñandeva of Porto Lindo (Jakarey) Yvy Katu \\ Este es nuestro cuerpo a la tierra: una conversación sobre los modos de \\ cuidado Avá Guarani/Ñandeva de Porto Lindo (Jakarey) Yvy Katu \\ Yan Leite Chaparro ${ }^{1}$ \\ Eliezer Martins Rodrigues ${ }^{2}$ \\ Josemar de Campos Maciel $^{3}$
}

\section{Resumo:}

O escrito que segue é um recorte de uma pesquisa que por entre conversas sobre a noção de desenvolvimento com um pesquisador Avá Guarani/Ñandeva do território Porto Lindo (Jakarey) Yvy Katu, busca refletir sobre as complexidades sócio cosmológicas que envolve os modos de cuidado Avá Guarani/Ñandeva, ampliando o debate sobre a saúde das e nas sociedades indígenas. Seus caminhos e regimes de conhecimentos e práticas. Pois, conversar sobre a questão do desenvolvimento, consequentemente leva a pensar a saúde nos territórios indígenas.

Palavras-chave: os Avá Guarani/Ñandeva; Porto Lindo (Jakarey) Yvy Katu; modos de cuidado; sócio cosmológico; saúde.

\begin{abstract}
:
The following article is a portion of a research that through conversations about the notion of development with a researcher Avá Guarani/Ñandeva of Porto Lindo territory (Jakarey) Yvy Katu, seeks to reflect on cosmological socio-complexities involving the caretaking practices of Avá Guarani/Ñandeva, broadening the debate on the healthcare of and in indigenous societies and his ways and schemes of knowledge and practices. Because, talking about the issue of development, consequently, leads to thinking about health and healthcare in indigenous territories.
\end{abstract}

Keywords: the Guarani / Ñandeva Avá; Porto Lindo (Jakarey) Yvy Katu; healthcare; socio-cosmology; health

\footnotetext{
${ }^{1}$ Universidade Católica Dom Bosco/UCDB e Universidade Federal da Grande Dourados/UFGD.

2 Território Guarani Ñandeva Porto Lindo (Jakarey) Yvy Katu e Secretaria Municipal de Educação de Japorã/MS.

${ }^{3}$ Universidade Católica Dom Bosco/UCDB.
} 


\section{Resumen}

El escrito que sigue es un recorte de una investigación que entre conversaciones sobre la noción de desarrollo con un investigador Avá Guarani/Ñandeva del territorio Porto Lindo (Jakarey) Yvy Katu, busca reflexionar sobre las complejidades sociológicas cosmológicas que rodean los modos de cuidado Avá Guarani/Ñandeva, ampliando el debate sobre la salud de y en las sociedades indígenas. Sus formas y esquemas de conocimiento y prácticas. Para, al hablar sobre el tema del desarrollo, en consecuencia lleva a pensar sobre la salud en los territorios indígenas.

Palabras clave: Los Avá Guarani/Ñandeva; Porto Lindo (Jakarey) Yvy Katu; modos de cuidado; sócio cosmológico; salud.

\section{Nota introdutória}

O que segue é a organização de conversas durante o trabalho de pesquisa de campo com um pesquisador Avá Guarani/Ñandeva, e reflexões junto com dois pesquisadores não-indígenas. Movimento que se aproxima da possibilidade de produzir simetrias em relação a produção de conhecimentos e politicas no campo da questão e das questões indígenas. Proposta que tem como objetivo, tecer uma maior conversa como fenômeno de reflexividade, que faz pensar a questão da saúde indígena como um processo marcado por alteridades, atravessamentos e pacificações (sobre aquilo que não é bom). Por isso, a organização textual inscrita aqui utiliza o itálico para as palavras indígenas e o não itálico para as palavras não-indígenas, com o objetivo de identificar os textos sem perder a distância e a diferença.

Manuscrito que esta organizado por três momentos: o primeiro momento apresenta o dono das palavras guardadas, o pesquisador Avá Guarani/Ñandeva Eliezer Martins e o território do qual ressoa as palavras. O segundo momento são as palavras produzidas a partir de encontros e conversas durante a pesquisa de campo sobre o tema do "desenvolvimento" que consequentemente nos leva a pensar sobre a saúde indígena, e seus muitos atravessamentos que eles fazem dentro e fora do território. E o terceiro momento são alguns comentários reflexivos com o objetivo de pensar esses atravessamentos e os modos de cuidados produzidos pelos Avá Guarani/Ñandeva de Porto Lindo (Jakarey) Yvy Katu.

\section{Apresentações}

O dono das palavras é o pesquisador Avá Guarani/Ñandeva Eliezer Martins Rodrigues, que esta aqui como um dos autores. Com ele foi possível tecer conversas sobre o tema do "desenvolvimento", pois Eliezer possui uma longa trajetória como professor no território Porto Lindo (Jakarey) Yvy Katu, graduado em ciências sociais, mas também trabalhou por aproximadamente dez anos como cortador de cana de açúcar nos canaviais das usinas de etanol no sul do Mato Grosso do Sul, e no ano de 2018 defendeu sua dissertação de mestrado em educação relacionado ao tema da criança Avá Guarani/Ñandeva.

Dessa forma, as palavras guardadas de Eliezer Martins que nunca sai de si (DERRIDA, 1994) ressoam sobre a realidade do território Porto Lindo (Jakarey) Yvy Katu. Pesquisador que conhece de dentro e de fora o território que vive, como pessoa cotidiana, professor, pai e atento sempre as palavras dos rezadores e rezadoras que exibem sempre suas belas palavras para aqueles que escutam sensivelmente. As palavras guardadas de Eliezer Martins, lembra Clastres (2012) sobre os Últimos Homens, aqueles que por excelência são grandes filósofos, e produzem uma filosofia onde a poética e a estética caminham juntas, diferente da filosofia ocidental que ainda trilha seus caminhos divorciado da poética. Filosofia que fala do território, das complexidades sócio cosmológicas e cosmo políticas Avá Guarani/Ñandeva. 
Território descrito da seguinte forma pelo pesquisador Eliezer Martins (2006).

Então pra gente defender a nossa terra, a nossa terra lá no Porto Lindo, conforme o cacique Delossanto, eu conversei com ele quando soube que tinha um encontro aqui pra gente falar da terra, ele disse que a terra pra nós é um chão. É o chão onde vamos cultivar as riquezas que a gente tem de dentro de nós, que são as músicas assim em guarani, que a gente brinca com as crianças. O chão pra nós é especial pra entender, pra fortalecer nossa dança e vai fortalecer a língua que hoje esta quase, pra mim está, em perigo de acabar mesmo nossa língua guarani. O modo de ser, porque aqui a gente fala da nossa língua, a gente dança, mas nós não praticamos esses rituais quando a gente vai nas reuniões da cidade. E, também, falar no espaço é dizer que a terra vai servir para repassar tudo que a gente tem, de acordo coma nossa visão pras criança. [...] O que importa pra nós é que ali nós vamos manter nosso modo de ser, mesmo tendo os não-índios, mesmo que nós perdemos nossa árvores, os pássaros, os rios. O que nós perdemos ali, isso não importa pra nós. O que vai ser importante pra nós é ocupar aquela terra que é nossa. Estou falando da terra que é o Yvy Katu, da aldeia Porto Lindo. Então, de acordo com o Delossanto, que é rezador, inclusive ele esta morando na área de conflito, já fez o barraquinho dele lá, há muitas necessidades onde nós perdemos, onde nós deixamos. Ele diz que não deixou aquela terra porque sabia que um dia nós retornaríamos lá e já aconteceu, no Yvy Katu. Ee é um desafio. Antes nós lutamos, ele falou, com arco e a flecha, mas hoje nós temos uma lei que diz que garante a terra pra nós. Mas se a gente não tivesse se movimentado, igual fizemos no Yvy Katu, nós até hoje estaríamos lá naquele 1.600 hectares que a Funai deu [...] Então, chegou o momento que nós dissemos e falamos pro rezador: não, vocês que conhecem a reza que vai servir pra nos fortalecer. E essa é a nossa arma, a reza [...] Nós deixamos pra trás e vivemos de novo aquilo que nós vivemos há anos atrás, e enfrentamos nossos adversários políticos, é a questão da terra. E a aldeia completa veio de novo. Nós entramos de novo no Yvy Katu, no Porto Lindo, e estamos lá de novo hoje [...] Essa terra vai servir pra mantermos a língua e hoje a língua guarani é muito difícil pra nós. É, como a reza voltar, para isso o espaço vai ajudar em muitas coisas do nosso modo de ser. Conforme o rezador a terra é a arma nossa. A arma nossa vai ser a nossa vida lá. Se chegar alguém com arma o que nós vamos pôr na frente é a nossa vida, ali. E eu acho que, conforme o Delossanto, o rezador, ele fala mais sobre a vida dele, porque os mais velhos já perderam, o tanto que já perderam! (p.143 e 144)

Processo histórico relato por Eliezer Martins a partir de conversas com o rezador Delossanto. Explicitando o processo de espoliação e sequestro dos seus territórios, e o presente histórico de retomada desses mesmos territórios sequestrados. Processo articulado continuamente com a terra, o modo Avá Guarani/Ñandeva de viver e de cuidar. Processo descrito por Colman (2007) da seguinte forma:

A Terra Indígena de Yvy Katu se localiza próxima a Reserva de Porto Lindo, município de Japorã. Yvy Katu está à $510 \mathrm{Km}$ de Campo Grande, no extremo sul do Estado de Mato Grosso do Sul. A reocupação deve ser uma ampliação da atual reserva de Porto Lindo. A terra indígena de Yvy Katu é área já identificada e possui 9.461 ha e foi ocupada por 1500 guarani, da reserva de Porto Lindo, que não suportavam mais a situação de aperto e de confinamento em que se encontravam na antiga reserva. Nestas condições era praticamente impossível a vivência do modo de ser guarani. (p. 65)

Território que pode ser observado pelo mapa que segue, produzido por Landa (2005), onde é possível identificar os limites geográficos do grande território Porto Lindo (Jakarey) Yvy Katu, que com a ampliação pode chegar a 9.416,4429 hectares (MURA, 2002) segundo o laudo antropológico de homologação e demarcação do território. Permitindo assim, o modo de vida e de existir Avá Guarani/Ñandeva, que podemos traduzir como: permitindo a produção de saúde pelos Avá Guarani/Ñandeva. 


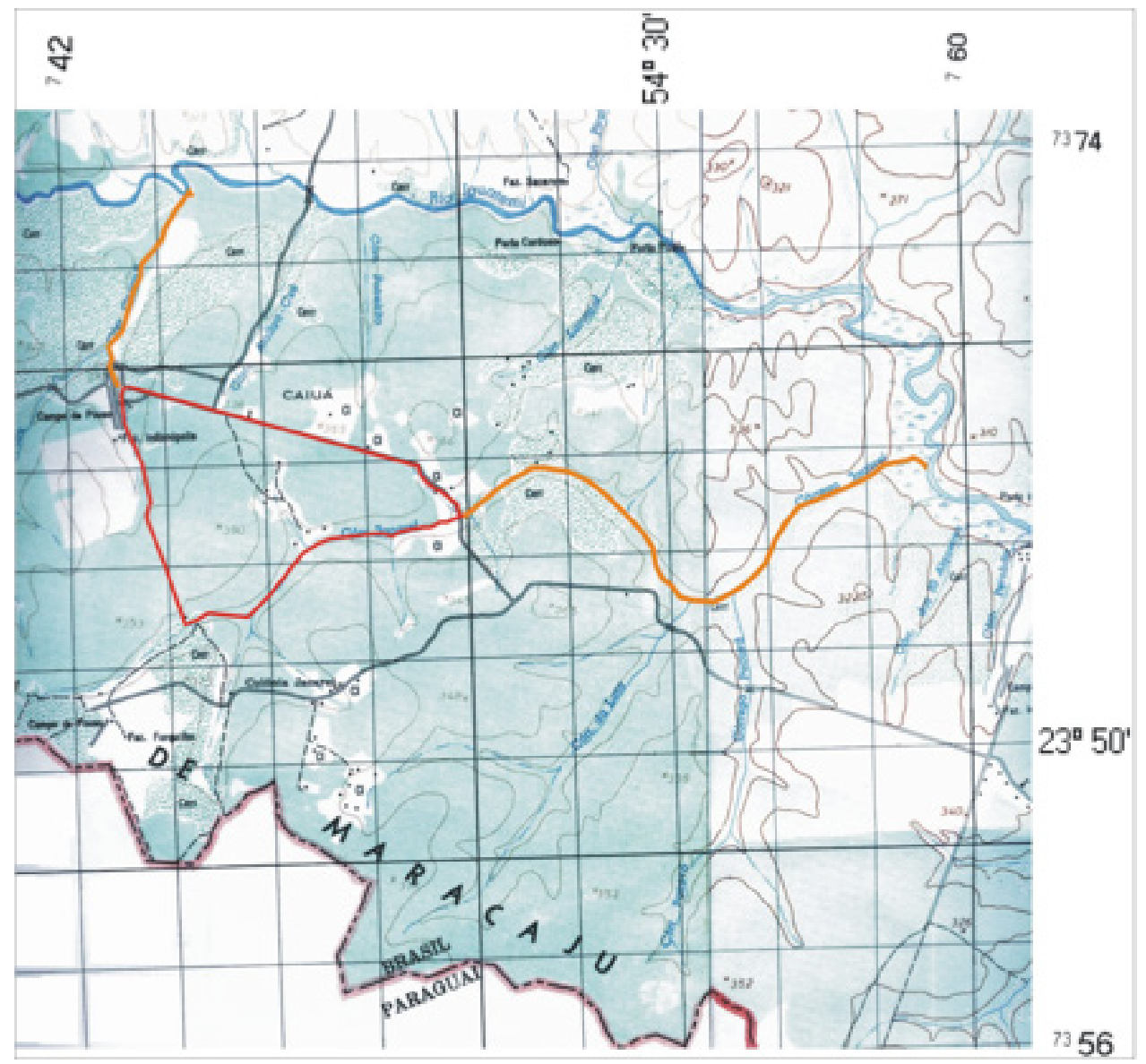

Figura 1 - Mapa com a TI Porto Lindo/Jakarey (em vermelho) e a área do tekoha Yvy Katu (em laranja). A porção norte é limite como rio Iguatemi. (LANDA, 2005)

\section{As palavras ${ }^{4}$}

Parece não, é, por que o rezador (Cantalicio Godoi) ali falou sobre, falou sobre isso que é pra nós, isso que é pra nós, o povo Guarani ser completo. A gente tem a nossa reza; pra rezar a gente precisa da água, água limpa, do mato, do vento. Falo do vento, que o peixe, tem um saquinho dentro do seu corpo, ele tem um saquinho, quando acaba o vento ele sai um pouquinho pra fora, puxa, puxa um pouquinho pra dentro o ar; aí ele vai debaixo d'água de novo. O rezador falou assim, por isso que o vento é importante também pros peixes. Então o Guarani precisa disso, da reza pra manter vivo essa água limpa, o vento, o mato, tudo que é importante pra nós.

Como os remédios do mato, eles são pra curar as doenças. Quando meu tio (Sabino Dias) fala que a gente tem que plantar remédios caseiros, ele diz que não é pra proteger somente a família, mas também as pessoas que vem de longe, para o vizinho. Então é uma proteção cultural, que vai ajudar, e isso ele chamou de desenvolvimento pra cultura Guarani. Porque o preparo de remédio verdadeiro, meu tio sabe preparar, ele sabe o tempo, por exemplo agora (de julho até agosto) é um mês muito bravo assim, se podemos dizer. Que precisamos cuidar do nosso corpo.

Esse é um modo de pensar muito diferente do povo que fala que é civilizado, Porque a gente é diferente, temos nosso próprio modo de ser. Somos diferente do povo da sociedade nacional, o moderno.

\footnotetext{
${ }^{4}$ Palavras de Eliezer Martins Rodrigues a partir de reflexões e conversas tecidas durante a pesquisa de campo de doutorado em Porto Lindo (Jakarey) Yvy Katu. Conversas que tiveram como guia central o pensar sobre a ideia e as questões de "desenvolvimento".
} 
Então pra outros povos, pra outras culturas, nós somos muito inferior, a gente não trabalha, a gente não se desenvolve, a gente não constrói, a gente não um monte de coisas. Parece em relação as coisa pra os outros povos, que nós estamos parados, que a gente não faz nada.

Mas isso são equívocos, eu falei pra você. Parece que o povo Guarani não vai nunca se desenvolver, mesmo se tiver bastante terra. Por isso que a maioria fala: por que o indio quer terra se não trabalha? Né. E nesse pedaço de terra, da retomada mesmo, a gente conseguiu um pedacinho do mato, você viu lá, e nesse pedacinho do mato, ali tem, ali tem, vamos dizer assim, milhões e milhões de dinheiro, vamos dizer assim, que custa dinheiro pra nós. A gente não vai vender nunca esse pedacinho do mato, porque ali, ali a gente, dali a gente vai tirar, a gente vai tirar. Primeiro vários tipos de remédio, não é só um remédio só.

A gente vai tirar algumas taquarinha que tem pra gente fazer artesanato; a gente vai tirar flores pra enfeitar o altar quando vai acontecer o batismo das criança; a gente vai tirar taquarinha pras mulheres fazer as cestinhas; a gente vai buscar lenha; a gente vai cuidar dos passarinhos; a gente vai entrar na sombra natural, porque tem dia que a gente vai no mato com a família. A gente deixa tudo as coisa que não é do índio: televisão, moto, a gente tem dia que a gente encosta e deixa de lado as coisa do não índio e a gente vai no mato com a familia. A gente vai olhar as plantas medicinais, a gente vai olhar os passarinhos, ouvir os passarinhos. Isso é um lazer pra nós isso aí. As crianças vão brincar no mato, a gente vai encontrar algumas frutas, no caso o jabuticaba mesmo e aí a gente relembra dos nossos avós, tudo isso, esse pouquinho de mato, um pé de jabuticaba já relembra já, já começa lembrar nossa história, quem somos realmente.

Vamos pro mato e fazemos nossas memórias. Então tudo isso ajuda a fortalecer a identidade, ajuda a construir, relembrar, a gente tem isso na memória, então a gente fala do valor das coisas que são pra gente, a gente fala do valor do mato para as crianças e as crianças começa a fazer, e dar valor nas nossas coisas. Então tudo isso que o meu tio falou, sobre as variedades da madeira, que ele falou também. Então quem vem de fora vê aqui e pensa que tudo esta parado, mas não esta, porque tem muita coisa acontecendo que quem vem de fora não consegue ver.

Eu falei das flores né, que existem várias variedades de flores que a gente usa no batismo das crianças. No batismo. Então, ai a gente tem que ir mesmo no mato. Como é que a gente vai na cidade né? Lá não tem mato. A gente vai no mato e vê a memória dos nosso passado. E a gente não deixa acabar o mato, a memoria, o batismo, a água, todas as coisas que são importantes pra nós.

Muito da nossa memoria esta no mato. Em casa tem flores do mato, agente pega palmeiras do mato que serve para as criança, a gente trás isso pra casa, que tem o cacho que a gente usa. A gente traz uns seis, cinco cacho já com flores, e coloca no altar. A gente faz o altar, e esse altar também é feito de cedro, madeira de cedro, o altar, pra gente fazer a reza. Você me deu aquela foto, você lembra? O nome do altar em Guarani é Tataendy. Ele é feito de cedro e a gente tem um ali dentro, a gente corta no meio a moringa e coloca água de Cedro. E depois a gente usa a pena do papagaio por exemplo e o outro pássaro que tem penas grandes, a gente usa a pena grande pra jogar água nas crianças. Pra fazer o batismo.

Por aqui onde estamos passando é o Betil, a mata do Betil. Aqui ainda tem bastante bicho, tem bastante passarinho aqui ainda. Essa mata a gente não mexe, então, por isso que eu trouxe você pra cá. Aqui esta bem dentro da aldeia. Aqui é bonito, bem bonito, aqui de manhã quando eu passo aqui para ir para escola esta bem frio. Tem uma trilha ali, onde faz a vizinhança entre parentes.

A moringa você tem que colocar água, junto com folha e a casca do cedro pra fazer o benzimento, pra rezar. E isso tudo já se prepara antes do batismo. Já tem que tá preparado já. Aí usa também pena de pássaro pra molhar a cabeça da criança. Então, por isso que eu falo, são essas coisas importantes pra nós, se a gente fazer isso, nós somos um povo completo.

A gente não procura mais outras coisas. E o que que a gente vai precisar, de um dia, um carro na hora do batismo? Não vai precisar. Na hora do batismo a gente esquece tudo as coisas do não índio. Isso nós ajuda. Agora a 
gente precisa, mas pra fortalecer, pra ficar, assim, contente, ficar assim seguro, pra gente ficar e dizer que a gente tá olhando pra cima, olhando pra Deus, a gente tem que fazer isso. Porque se a gente não fazer isso a gente não é mais ninguém. O rezador falou assim, o meu tio falou assim: Dia de hoje, muitos jovens tá aí andando a toa por aí. Ele falou a toa. Isso quer dizer que não tem pra onde ir. Tá sem caminho. Tá querendo ir no meio do povo que se diz desenvolvido, mas quem que ajuda ele pra se desenvolver? Tudo isso que te falei, e não as coisas do não-índio.

De acordo com o rezador (Cantalicio Godoi), o selvagem, pra muitos não indígena, entende de uma forma diferente, que selvagem pode ser uma pessoa, uma pessoa que não conhece nada. Mas na verdade o rezador fala assim que nós somos selvagens sim, porque somos e fomos batizados por Deus, por Nanderu Tupã, fomos batizados junto com o mato, com a floresta, porque o batismo aconteceu quando Deus, Tupã Ñanderu deu pra cada povo o seu território, e nós fomos batizados junto com a selva mesmo, o mato, com as plantas medicinais, as frutas, variedade de frutas.

E no mato tem os animais, os pássaros, é, a água e o mato junto, as árvores, as flores do mato, o cipó pra gente usar pra fazer a casa, e as madeiras que servem pra gente fazer a casa e os tipo de folhas que serve pra gente fazer a casa, e as frutas que as criança gosta, esta tudo junto, Deus, Tupã, batizou tudo junto. Então eu perguntei isso pro rezador por que será que é importante né, será que a gente aceita, ou a gente tem que aceitar ou não, porque a gente, por muitos não indígena, por outros povos, nós somos selvagem. Então selvagem, pros não indígena é algo inferior. Mas, selvagem pra nós, de acordo com o rezador, é algo importante porque fomos batizados por Deus, então se alguém falar que selvagem é ruim tá falando mal do Deus, que foi Deus que deu essa selva pra nós. Então todos esses remédios tradicionais, remédios dos animais, a importância dos animais, tá tudo relacionado à selva, o mato, por isso que é importante essa colocação do rezador que eu perguntei pro senhor Cantalício. Então é isso.

Os passarinhos tem muita ligação com a gente também. Olha só, tem alguns passarinhos que pra nossa cultura é muito importante, como o caso do beija-flor. O beija-flor. Esses dias chegou um beija-flor em casa, aí logo o meu gurifalou assim: Chegou um beija-flor ali pai. Ai eu falei: Não, tem pessoa importante que vai visitar nós aqui na aldeia. Ai ele perguntou: quem é? Aí é você. Falei: O professor doutor vai vir aqui, então isso é um sinal que vai vir gente importante. Uma visita, visita importante. O beija-flor é um passarinho que dá atenção pras crianças, não só pras crianças. Então, é um passarinho importante, não é um passarinho qualquer. A gente respeita muito esse passarinho e tem vários passarinhos, e pássaros que são muito respeitado pelos Guarani daqui de Porto Lindo e Yvy Katu.

Tem o beija-flor que te falei, tem também a coruja. A Coruja é um pássaro noturno. E ela tem ligação com as crianças: se a criança começa a ficar por aí de noite, num horário que não épermitido, porque a gente tem um horário que não é mais permitido para as crianças. Por exemplo, das $21 \mathrm{~h}$ até às $22 \mathrm{~h}$ horas da noite as crianças tão brincando ainda. Então a gente fala: a coruja tá pertinho já. Então já tá na hora das criançada deitar. Aí a coruja sempre fica perto da casa, e fica falando, e fica, assim, cantando, e se a criança começa a ouvir entra pra casa e já vai direto na cama. Então é um pássaro noturno que pra nós também cuida, a gente cuida das crianças junto com esse pássaro. Então é um pássaro muito importante. São vários pássaros, cada um tem a sua função, a ligação que a gente tem com eles.

\section{A gente cuida das crianças junto com esse pássaro: a saúde como organização sócio cosmológica ${ }^{5}$}

As palavras de Eliezer Martins desenham um sensível tecido atravessado por dimensões humanas e não-humanas, que precisam a todo momento serem administradas por constantes relações de alteridades. Consubstanciando a saúde como uma produção sócio cosmológica e sócio política, onde a

\footnotetext{
${ }^{5}$ As palavras guardadas Guarani que serão apresentadas durante o texto estão contextualizas durante a pesquisa de campo de doutorado, sendo assim, as perguntas e indagações são guiadas por conversas sobre a ideias e as questões de "desenvolvimento".
} 
todo instante o humano complementa e direciona relações com seres humanos e não-humanos, como com alguns animais, algumas plantas, a água e alguns seres encantados, ou deuses, que são guardiões de certos padrões de relações sociais que fazem a organização social cotidiana Guarani. Como lembra Izaque João (2011), pesquisador Guarani (Kaiowá/Pai'Tavyterã):

\begin{abstract}
No sistema tradicional kaiowá, as coisas materiais naturais possuem uma origem divina, ou seja, cada objeto pertence a uma determinada divindade. Cada época do ano, com seu clima diferenciado, são interpretados como um pilar da estrutura do mundo físico, os quais definem as regras sociais externas e internas do grupo, tais como: hábitos e comportamentos, a exemplo de tomar banho frio de madrugada, como forma de renovar o corpo e a alma, à semelhança do mundo físico que se renova ao final de cada inverno; estratégia política de relacionamento com os deuses, como uma reza específica para chamar a geada, para que esta termine de secar as plantas e, assim, haja condições de brotar novamente. Estas regras são fundamentais para a interação constante com o mundo sobrenatural através do canto e também e para o trabalho. Dessa maneira, o espaço ocupado pelos Kaiowá é entendido como o local político-social, o qual depende do processo da reza para o seu equilíbrio. (p. 33)
\end{abstract}

Caminho que Izaque João (2011) acrescenta quando revela que:

Ayvu é também o pássaro guardião e, para o Kaiowá, o corpo humano é entendido como o abrigo desse guardião, ou como uma casa que abriga diversos teko vảyra (guardiões incorporados no corpo). Quando a doença ataca a pessoa, esse pássaro se retira do seu corpo e sobrevoa no espaço. Por isso, na concepção do xamã, a doença é considerada como fogo se propagando lentamente pelo corpo humano: na ausência do ayvu, o corpo perde a força do movimento e fica impossibilitado de reagir. (p. 55)

Nesse sentido a saúde é produzida por uma série de relações, mediada pela reza e por regras, que conduzem a pessoa por bons caminhos, direcionamento que é comum, ou mesmo, que precisa ser entendido e produzido por um comum cotidiano. Uma complexa organização que necessita de uma escuta sensível para poder fazer dessa complexidade caminhos pensar com os Guarani seus modos de cuidado. Regime de conhecimentos e práticas que questiona e atravessa os modelos não-indígenas de saúde, muitos permeados pela invenção branca de desenvolvimento.

No mesmo caminho de Eliezer Martins e Izaque João, o pesquisador Joaquim Adiala Hara traz em uma conversa durante a pesquisa de campo a seguinte questão sobre o conceito de pessoa:

Y significa água, que é a primeira palavra de Tupã, Yvy significa terra, que é a segunda palavra de tupã, Yvyra significa planta, que é a terceira palavra de Tupã e Yvy Pora significa pessoa, que é a quarta palavra de Tupã. Entendeu, che amigo, para nós, os Guarani, nada esta separado, nós e todos do planeta terra somos guardiões do planeta. Isso que temos que estudar. Que a gente só existe por causa do Yvy. Se o Yvy Pora não cuidar do planeta, o planeta vai acabar. (Joaquim Adiala Hara, 2017)

Conceito de pessoa que enreda-se com as palavras guardadas de Eliezer Martins, o que exige de quem olha de fora, uma maior atenção para não perder os nós do fio de Ariadne (LATOUR, 2008), pois perder um nó, esta como perder relações fundamentais para as produções de modos de cuidados Guarani. Produções que são transferidas para o humano sempre uma complexidade como modo de existir que produz uma rede sensível e concreta que tem a pessoa relacionado com dimensões que fogem muitas vezes dos sistema de saúde não-indígena. O que faz a necessidade de se sintonizar com o pensamento Guarani, como lembrou Melià (2016), para poder assim, apreender e conviver um pouco do que é possível. 
Pensamentos Guarani que atravessam o tempo, pois esses mesmo Guarani, passam e passaram por processos de extrema violência por conta de projetos e planos de colonização. A Guerra da Tríplice Aliança, as intervenções da Cia Matte Laranjeira e da Colônia Agrícola da Grande Dourados, são alguns das ações que produziram um certo tipo de confinamento (BRAND, 1997), no qual espoliaram e expulsaram os Guarani dos seus territórios. E são esses mesmos Guarani que sofreram e sofrem violência cotidianas por buscar seus territórios e a Terra Sem Mal (NIMUENDAJU, 1987 e CLASTRES, 2014) que falam e trazem em si palavras guardadas de extremo refinamento sobre como cuidar, movimento que transita da pessoa para tudo que exige vida. Modo de cuidado que ao cuidar da pessoa, cuida do que circula como vida cotidiana (a terra, a água, as plantas, os animais, o mato e as outras pessoas).

Cuidar que pode ser ouvido nas palavras guardadas do rezador Cantalicio Godoi. Palavras que foram ouvidas e transcritas durante a pesquisa de campo orientadas e guiadas por Eliezer Martins. Cantalicio Godoi quando perguntado sobre a ideia e as questões que envolve o conceito de "desenvolvimento" revela as seguintes palavras:

Presta atenção, este é nosso corpo a terra, tem espirito porque sem espirito nós nem vamos levantar [...] Como a água. A água é muito importante para nós. Para que vivemos, não só para os indígenas, para todo o mundo. A água é como a nossa mãe [...] Não podemos viver sem a agua, nós falamos que desmamamos, mas não dá água. [...] E o vento, olha bem, por causa do vento o nosso corpo caminha. [...] O vento nos ajuda, a gente se levanta com vento, o nosso corpo, o nosso sangue, o vento ajuda nós. Isso não pode estar contaminado. Os brancos usam veneno e isso vai pelo vento, eles usam avião. [...] Para nós, a terra esta assim, a madeira esta cheia de cupim, já esta comendo tudo por cupim. [...] Os não-indígenas não podem continuar porque só sabem fazer com papel e por isso o nosso canto é o que brilha o relâmpago. [...] O que é nosso é o que é de verdade, que é da terra, e é isso que temos que escutar isso não tem em nenhum lugar. Em nenhum papel. [...] O que é nosso é o mesmo que o relâmpago dos Tupã, é nosso e é deles. [...] Lembre-se de mim; depois vai vir vento forte, vai tirar do chão as casas dos brancos [...] Quer dizer que eles querem ser mais inteligente que o nosso Deus, que o nosso criador eles querem ser mas inteligente. Nosso Deus manda granizo, mostra o que ele é para os brancos; eles aparentemente não têm pressa porque suas casas são bonitas, aparentemente. Mas para o nosso Criador isso não é nada, e por isso que manda raio e inundações. Os carros ficam todos no chão. Para ver se eles compreendem. Esse canto é quando vem um vento forte. Quando a gente ergue a cabeça eles já enxerga nós, porque nós não nos escondemos deles, nem um pouquinho. Com aquele espelho grande ele nós $v e ̂$ a todos. Por isso que nós rezamos, dançamos, cantamos. Os deuses nos respeitam porque as coisas deles nós os levantamos para eles. (Cantalicio Godoi, 2017).

Palavras do rezador Cantalicio Godoi que fecha, o limite desse texto, e inicia um longo caminho para pensar os modos de cuidado Avá Guarani/Ñandeva. Uma forma e conteúdo que precisa ser apreendido: primeiro, para uma maior sofisticação da ação dos sistemas não-indígenas com os Guarani; segundo, pois revela um conhecimento histórico, de uma sociedade própria que se mantem ela mesma, viva, resistente, mesmo sofrendo no passado e no presente severos processos de violência; e terceiro, pois são conhecimentos e práticas que podem intervir no fim do mundo, pois possuem as coisas dos deuses, ou mesmo, apreender com os Guarani, esta como aprender a possibilidade do não fim do mundo sempre profetizado pela sociedade da invenção branca de desenvolvimento.

Então, presta atenção, para os Guarani o corpo é a terra, e terra é o corpo. Nunca foi um recurso possível de higienização ou de venda. Este é o nosso corpo a terra. São as palavras de um sábio ancião Avá Guarani/Ñandeva que denuncia e deixa um recado para o branco que usa veneno que mata o ar, a água, as plantas, os animais e os humanos. E faz lembrar para aqueles que chegam de longe vestidos de alguma coisa, como eu que cheguei como pesquisador e psicólogo, que é necessário produzir uma escuta sensível para ouvir as palavras guardadas Guarani, e nunca perder o rosto (LÉVINAS, 2005) desses que estão sempre perto e que exige como forma de tra- 
balho, a produção de uma aliança de amizade, de caminhar ao lado, com eles, e não sobre. Pois, para conversar sobre modos de cuidados, antes de tudo é necessários entender a simetria que já existe.

As intenções desse manuscrito foi despertar para quem chega, o leitor e a leitora, que muitas vezes não esta familiarizado com o tema, que no caso da formação em psicologia no Brasil é algo corriqueiro. Uma aproximação com algumas inicias questões sobre os modos de cuidados de uma sofisticada sociedade indígena, os Guarani, nesse caso, os Avá Guarani/Ñandeva que vivem no território Porto Lindo (Jakarey) Yvy Katu no sul do Estado do Mato Grosso do Sul, fronteira com o Paraguai, e que nesse instante lutam para retomar seus territórios de direito.

\section{Referências}

BRAND, Antônio. O impacto da perda da terra sobre a tradição Kaiowá/Guarani: os difíceis caminhos da palavra. Tese de doutorado. PUC/RS: Porto Alegre, 1997.

CLASTRES, Pierre. A Sociedade Contra o Estado. São Paulo: Cosac \& Naify, 2012.

COLMAN, Rosa. Território e sustentabilidade: os Guarani e Kaiowá de Yvy Katu. Dissertação de mestrado. UCDB: Campo Grande, 2007.

JOÃO, Izaque. 2011. Jakaira Reko Nheypyrũ Marangatu Mborahéi: origem e fundamentos do canto ritual jerosy puku entre os kaiowá de panambi, panambizinho e sucuri'y, mato grosso do sul. Dissertação de mestrado. UFGD: Dourados, 2011.

CLASTRES, Pierre. Investigaciones en antropologia política. Barcelona: Gedisa Editora, 2014

DERRIDA, Jacques. A voz e o fenômeno. Rio de Janeiro: Editora Zahar, 1994.

MELIÀ, Bartomeu. Camino Guaraní/Guarani Rape: de lejos venimos, hacia más lejos caminamos/mombyrygui niko jaju, mombyryénte ko jaguata. Asuncíon: Centro de Estudios Paraguayos “Antonio Guasch", 2016.

LANDA, Beatriz. Os Ñandeva/Guarani e o uso do espaço na terra indígena Porto Lindo/Jakarey, município de Japorã/MS. Tese de Doutorado. PUC/RS: Porto Alegre, 2005.

LATOUR, Bruno. Jamais Fomos Modernos. 4ª Reimpressão. Rio de Janeiro: Editora 34, 2008.

LEVINAS, Emmanuel. Entre nós: ensaios sobre a alteridade. 2a ${ }^{\text {a }}$ Ed. Petrópolis: Editora Vozes, 2005.

NIMUENDAJU. Curt. As lendas da criação e destruição do mundo como fundamentos da religião dos Apapocúva-Guarani. São Paulo: Editora HUCITEC, 1987.

MARTINS, Eliezer. A terra como chão sagrado e o valor cultural. Revista Tellus. Campo Grande/MS, ano 6. n. 10. p. $143-145,2006$.

MURA, Fábio. (Coord. Do GT); ALMEIDA, Rubem F.T. Relatório antropológico de revisão de limites da T.I. Porto Lindo (Jakarey): Terra Indígena YVY KATU. Portaria n. 724/PRES, 2002. 
